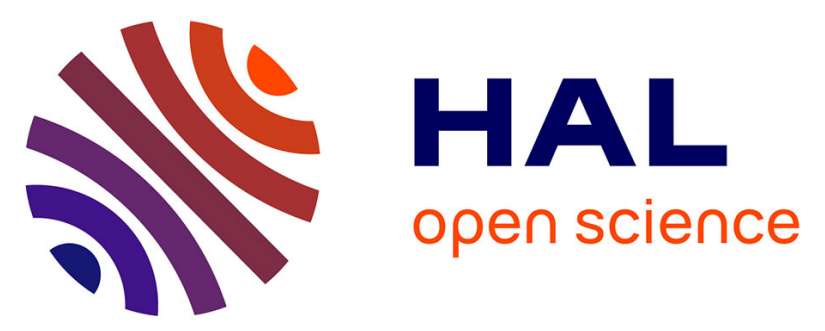

\title{
X-ray absorption study on the origin of the deviation from Vegard's law for U(Al1-xGex)3 solid solution
}

\author{
S. Le Tonquesse, M. Pasturel, Valérie Demange, A. Tayal, P.L. Solari, C.
} Prestipino

\section{- To cite this version:}

S. Le Tonquesse, M. Pasturel, Valérie Demange, A. Tayal, P.L. Solari, et al.. X-ray absorption study on the origin of the deviation from Vegard's law for U(Al1-xGex)3 solid solution. Journal of Nuclear Materials, 2019, 526, pp.151772. 10.1016/j.jnucmat.2019.151772 . hal-02310250

\section{HAL Id: hal-02310250 \\ https://hal-univ-rennes1.archives-ouvertes.fr/hal-02310250}

Submitted on 20 Dec 2021

HAL is a multi-disciplinary open access archive for the deposit and dissemination of scientific research documents, whether they are published or not. The documents may come from teaching and research institutions in France or abroad, or from public or private research centers.
L'archive ouverte pluridisciplinaire HAL, est destinée au dépôt et à la diffusion de documents scientifiques de niveau recherche, publiés ou non, émanant des établissements d'enseignement et de recherche français ou étrangers, des laboratoires publics ou privés.

\section{(ㄷ)(1) $\$$}

Distributed under a Creative Commons Attribution - NonCommerciall 4.0 International 


\title{
X-ray absorption study on the origin of the deviation from Vegard's law for $\mathrm{U}\left(\mathrm{Al}_{1-x} \mathrm{Ge}_{x}\right)_{3}$ solid solution
}

\author{
Sylvain Le Tonquesse ${ }^{\mathrm{a}}$, Mathieu Pasturel ${ }^{\mathrm{a}}$, Valerie Demange ${ }^{\mathrm{a}}$, Akhil Tayal $^{\mathrm{b}}$, \\ Pier Lorenzo Solari ${ }^{\mathrm{b}}$, Carmelo Prestipino ${ }^{\mathrm{a}, *}$ \\ ${ }^{a}$ Univ Rennes, CNRS, ISCR-UMR6226, F-35000, Rennes, France \\ ${ }^{b}$ Synchrotron SOLEIL, L'Orme des Merisiers, BP 48, St Aubin, 91192 Gif sur Yvette, \\ France
}

\begin{abstract}
The cell parameter evolution along the cubic $\mathrm{U}\left(\mathrm{Al}_{1-x} \mathrm{Ge}_{x}\right)_{3}$ solid solution shows a significant deviation from Vegard's law. The origin of such deviation has been investigated by X-ray powder and electron diffractions, EXAFS and HERFD XANES at the $\mathrm{U} \mathrm{L}_{3}$ and Ge $\mathrm{K}$ edges and specific heat measurements. The results of such investigations show that, from the structural point of view, $\mathrm{U}\left(\mathrm{Al}_{1-x} \mathrm{Ge}_{x}\right)_{3}$ does not present any local or long range ordering and the deviation from Vegard's law is caused by valence instability of $U$ with an actual decrease of the U-Ge bond length with increasing Al-content and cell parameter.
\end{abstract}

\section{Introduction}

Similarly to silicon, germanium added to the nuclear material $\mathrm{UAl}_{3}$ was shown to efficiently block the formation of the undesired $\mathrm{UAl}_{4}$ during the fabrication process or under irradiation by the reaction of the former with the 5 aluminium matrix in fuel plates or irradiation targets [1]. Moreover, it also has a protective role against the formation of the detrimental ternaries $\mathrm{UMo}_{2} \mathrm{Al}_{20}$ and $\mathrm{U}_{6} \mathrm{Mo}_{4} \mathrm{Al}_{43}$ in $\gamma-\mathrm{U}(\mathrm{Mo}) / \mathrm{Al}(\mathrm{Ge})$ diffusion couples simulating prospective fuel plates based on these components [2]. A deep knowledge of the local and long range order of the $\mathrm{U}(\mathrm{Al}, \mathrm{Ge})_{3}$ solid solution is thus required to simulate as

\footnotetext{
* Corresponding author

Email address: carmelo.prestipino@univ-rennes1.fr (Carmelo Prestipino)
}

Preprint submitted to Journal of Nuclear Materials

August 20, 2019 
precisely as possible the reactivity and irradiation behavior of this fuel. But opposite to the case of $\mathrm{U}(\mathrm{Al}, \mathrm{Si})_{3}$ for which numerous data are available in literature $[3,4,5]$, scarce reports are available for the $\mathrm{U}(\mathrm{Al}, \mathrm{Ge})_{3}$ solid solution $[6,7]$.

The binary intermetallic compounds $\mathrm{UAl}_{3}$ and $\mathrm{UGe}_{3}$ crystallize in the $\mathrm{CuAu}_{3}$ structure-type (space-group $\operatorname{Pm} \overline{3} m$ ) where $\mathrm{U}$ is located at the $1 c$ and $\mathrm{Al}$ or $\mathrm{Ge}$ at the $3 a$ Wyckoff positions as shown in Fig. 1 (a). Because they crystallize in the same structure-type with relatively close lattice parameters and similar covalent radii ${ }^{1},\left(\mathrm{r}_{A l}=1.21 \AA\right.$ Aand $\left.\mathrm{r}_{G e}=1.20 \AA[10]\right)$, the existence of a total solid-solution as reported by Tyunis et al. [6] and later on by Moussa et al.

${ }_{20}[7]$ is not surprising. Indeed, similar pseudo-binary systems $\mathrm{USn}_{3}-\mathrm{UGa}_{3}, \mathrm{USn}_{3}-$ $\mathrm{UAl}_{3}[11]$ and $\mathrm{UAl}_{2}-\mathrm{UCo}_{2}$ [12] are solid solutions with a complete miscibility and present a conventional evolution of lattice parameters.

For solid solutions, lattice parameters are expected to vary linearly with the composition between the extremities, in accordance with the empirical Vegard's radii, as earlier suggested by Pauling and Huggins [14], implying that atomic volumes remain constant independently of the extent of the mixing. However this assumption has been experimentally proven only much later with the development of local range techniques such as EXAFS, because more common Bragg so diffraction techniques are based on the coherent scattering generated by long range order, i.e. the information obtained are averaged along many unit cells. For instance, in the seminal work of Mikkelsen and Boyce [15], for the first time a solid solution obeying to the Vegard's law, namely zinc-blende $\operatorname{In}_{x} \mathrm{Ga}_{1-x} \mathrm{As}$ (S.G. $F \overline{4} 3 m$ ), has been investigated as a function of the composition by EX-

35 AFS spectroscopy and diffraction. Bond distances derived from diffraction go from $2.45 \AA$ for GaAs to $2.62 \AA$ for InAs. However, EXAFS detects that lattice

\footnotetext{
${ }^{1}$ Metallic radii more commonly used in the intermetallics community are also similar, although the actual metallic radius of Ge is less clearly defined $\left(r_{A l}^{\text {metal }}=1.432 \AA\right.$ and $r_{G e}^{m e t a l}=1.378 \AA$ for Teatum [8] and $r_{G e}^{m e t a l}=1.43 \AA$ for Batsanov [9]
} 
induced strain affects linearly the bond only up to $-2 \%$ and $+1 \%$, for As-In and As-Ga bonds and consequently two almost constant but clearly different distances are present for all solid solution compositions.

However, although the similitude with the other U pseudo-binary system, both Tyunis et al. and Moussa et al. [6, 7] reported that the lattice parameter of the $\mathrm{U}\left(\mathrm{Al}_{1-x} \mathrm{Ge}_{x}\right)_{3}$ solid-solution deviates negatively from linearity and thus violate the Vegard's law. A valence instability of uranium or relative size effects of the $p$-element were evoked, respectively, to explain this observation.

In the present study, a local structure examination of $\mathrm{U}\left(\mathrm{Al}_{1-x} \mathrm{Ge}_{x}\right)_{3}$ intermetallics with $\mathrm{x}=0,0.25,0.5,0.75$ and 1 using EXAFS and XANES measurements at $\mathrm{U} \mathrm{L}_{3}$ and Ge K-edges has been performed to better understand the structural origin of such deviation and improve the comprehension of chemical bonding in this potential nuclear material.

\section{Experimental}

Polycrystalline ingots with nominal compositions $\mathrm{U}\left(\mathrm{Al}_{1-x} \mathrm{Ge}_{x}\right)_{3}$, with $\mathrm{x}=$ $0,0.25,0.5,0.75$ and 1 , were prepared by arc melting stoichiometric amounts of elemental components (all purities $\geq 99.5 \%$ ). The sample were turned upside down and remelted twice to ensure homogenisation. A subsequent annealing was performed at $973 \mathrm{~K}$ for two weeks after enclosing the samples in evacuated silica tubes. Resulting samples have been investigated by X-ray diffraction (XRD) using a Bruker D8 Advance diffractometer $(\theta-2 \theta$ Bragg-Brentano geometry, monochromatized $\mathrm{Cu} \mathrm{K} \alpha_{1}, \lambda=1.5406 \AA$ ) on powders obtained by manually grinding the ingots in an agate mortar. XRD data were modelled with the help of the FullProf code [16]. Scanning electron microscopy was performed using a JEOL JSM 7100 F microscope while electron diffraction and elemental analysis (Energy dispersive spectroscopy,EDS) were performed by transmission electron microscopy on a JEOL $2100 \mathrm{LaB}_{6}$ instrument operating at $200 \mathrm{kV}$. To select the smallest particles, powders were suspended in ethanol before deposition on ${ }_{65}$ copper grids. Then the grids were kept for a few minutes in air to let the solvent 
evaporate.

For X-ray absorption spectroscopy, the $\mathrm{U}\left(\mathrm{Al}_{1-x} \mathrm{Ge}_{x}\right)_{3}$ powders $(\approx 10 \mathrm{mg})$ were diluted with cellulose in order to achieve a maximum absorbance of $\approx 2$, pressed into pellets and then doubled confined in Kapton tape and polyethylene foil. The measurements were carried out on MARS beamline at SOLEIL synchrotron (Saint-Aubin, France) [17]. The X-ray beam energy for measurement at the U L3-edge was selected and scanned using a sagittal focusing $\mathrm{Si}(220)$ crystals monochromator and harmonic rejection has been performed by the use of a couple of Pt coated mirrors with an angle of $3.1 \mathrm{mrad}$. For the measurement at the Ge K-edge, sagittal focusing $\mathrm{Si}(111)$ crystals monochromator and Pt mirrors angle of $2.2 \mathrm{mrad}$ were used instead. Extended X-ray Absorption Fine Structure (EXAFS) data have been collected at Ge K edge $(11403 \mathrm{eV})$ and at $\mathrm{U} \mathrm{L}_{3}$ edge $(17166 \mathrm{eV})$ in transmission mode using specific intensity monitors with silicon diodes. Energy calibration has been monitored by measuring simultaneously the absorption of reference sample with residual photons ( $\mathrm{Y}$ and $\mathrm{Ge}$ foils for $\mathrm{U} \mathrm{L}_{3}$ and Ge K edge, respectively). High Energy Resolution Fluorescence Detection (HERFD) X-ray absorption has been also collected on Ge $\mathrm{K}$ edge and at $\mathrm{U} \mathrm{L}_{3}$ edge using a spectrometer equipped with a $\mathrm{Si}(660)$ or $\mathrm{Ge}(777)$ secondary monochomator crystal selecting Ge K-L $\mathrm{L}_{3}(9886 \mathrm{eV})$ and $\mathrm{U} \mathrm{L}_{3}-\mathrm{M}_{5}(13615 \mathrm{eV})$ signals, 85 respectively. For every compositions $\mathrm{U}\left(\mathrm{Al}_{1-x} \mathrm{Ge}_{x}\right)_{3}(\mathrm{x}=0,0.25,0.5,0.75$ and 1) fine structures $\mu(\mathrm{E})$ after the $\mathrm{U} \mathrm{L}_{3}$ and Ge $\mathrm{K}$ edges were measured and converted into $\chi(\mathrm{R})$ by Fourier transform using 1, 2 and $3 \mathrm{k}$-weight and Hanning window with $\mathrm{dk}=1$. The k-range used for the Fourier transform where 3.5 $15 \AA^{-1}$ both for the Ge $\mathrm{K}$ and $\mathrm{U} \mathrm{L}_{3}$ edges. The fitting procedure was realized simultaneously on the $\chi(\mathrm{R})$ of both edges over a range of 1.6 - $3.6 \AA$ for $\mathrm{Ge} \mathrm{K}$ and $1.6-4 \AA$ for $\mathrm{U} \mathrm{L}_{3}$. The coordination spheres around $\mathrm{U}$ and $\mathrm{Ge}$ as determined from XRD was used to calculate phase and amplitudes employed as initial model for fitting procedure. Reduction and modelling of the data were realized using the IFEFFIT code as implemented in the Athena and Artemis softwares [18]. Finally XANES simulation has been performed using FEFF8.4 code in the muffin-tin real space : full multiple scattering approach. Self-consistent poten- 
tial calculations were performed using Hedin-Lundqvist self-energy in a cluster containing around 100 atoms

\section{Results}

Samples of composition $\mathrm{U}\left(\mathrm{Al}_{1-x} \mathrm{Ge}_{x}\right)_{3}$ with $\mathrm{x}=0,0.25,0.5,0.75$ and 1 were synthesized and analyzed by powder diffraction (PD). The patterns of all the compositions are indexed with the cubic $\mathrm{CuAu}_{3}$ structure-type $(P m \overline{3} m)$ and only a small amount of UC impurity $(F m \overline{3} m)$ could be detected on the pattern of $\mathrm{UAl}_{3}$ (Figure 1b). Le Bail refinements of the $\mathrm{UAl}_{3}$ and $\mathrm{UGe}_{3}$ patterns converges to lattice parameters of $4.2676(1) \AA$ and $4.2078(2) \AA$, respectively, in good agreement with literature data $[19,20]$. By assuming the solid-solution to follow the Vegard's law, compounds with intermediate composition are expected to have a lattice parameter following the linear relation:

$$
a=-0.0199 \cdot x+4.2676 \AA .
$$

However, experimental lattice parameters found for $x=0.25,0.5$ and 0.75

110 example, in the closely related $\mathrm{UAl}_{3}-\mathrm{USi}_{3}$ system, crystallizing in the same $\mathrm{CuAu}_{3}$ structure-type $(P m \overline{3} m)$, Meshi et al. observed the appearance of satellite 
(a)

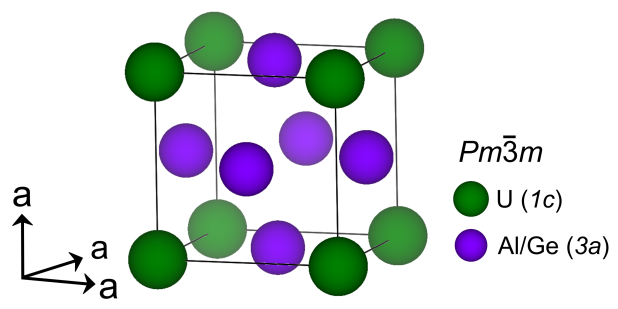

(b)

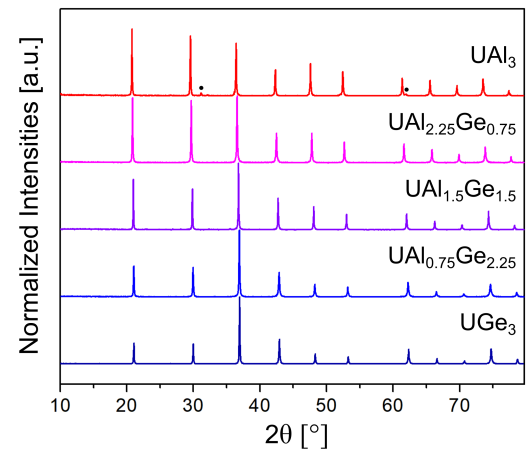

Figure 1: (Color online) (a) Structure of $\mathrm{UAl}_{3}$ and $\mathrm{UGe}_{3}$ crystallizing in the $\mathrm{AuCu}_{3}$ structuretype $(P m \overline{3} m)$; (b) powder XRD patterns of the $\mathrm{U}\left(\mathrm{Al}_{1-x} \mathrm{Ge}_{x}\right)_{3}$ samples with $\mathrm{x}=0,0.25,0.5$, 0.75 and 1 . The reflections marked with black dots $(\cdot)$ on the $\mathrm{UAl}_{3}$ pattern correspond to the UC impurity

reflections on the XRD patterns which are explained by the ordering of $\mathrm{Al}$ and $\mathrm{Si}$ on the $3 c$ site leading to the formation of a tetragonal superstructure $(I 4 / \mathrm{mmm})$ with lattice parameters $\mathrm{a}_{t} \approx 2 \mathrm{a}_{0}$ and $\mathrm{c}_{t} \approx 4 \mathrm{a}_{0}$. [4] In our case, no satellite reflections could be detected in any of PXRD patterns, however in order to exclude any ordering at lower range, electron diffraction, which is more sensitive to fine diffraction features, was realized on several grains of powders of compositions $\mathrm{UAl}_{1.5} \mathrm{Ge}_{1.5}$ and $\mathrm{UAl}_{0.75} \mathrm{Ge}_{2.25}$ which show the most severe deviation from the Vegard's law.

The electron diffraction patterns recorded along the [001], [011] and [111] zone axis (Figure 2) could be fully indexed with the $\mathrm{CuAu}_{3}$ structure-type $(P m \overline{3} m)$ with similar lattice parameters to those determined from PXRD which confirmed the absence of satellite reflections and superstructure. Moreover all the patterns are composed of very sharp diffraction spots consistent with well crystallized matter and without any type of diffuse scattering which usually appear in case of short range ordering or clustering of atoms. Based on these observations, the $\mathrm{U}\left(\mathrm{Al}_{1-x} \mathrm{Ge}_{x}\right)_{3}$ compounds seem to be true alloys where the $1403 c$ site is randomly occupied by $\mathrm{Al}$ and $\mathrm{Ge}$ atoms. At the light of such findings , the origin of lattice parameters deviation form the Vegard's law should not 
relate to structural arrangement.
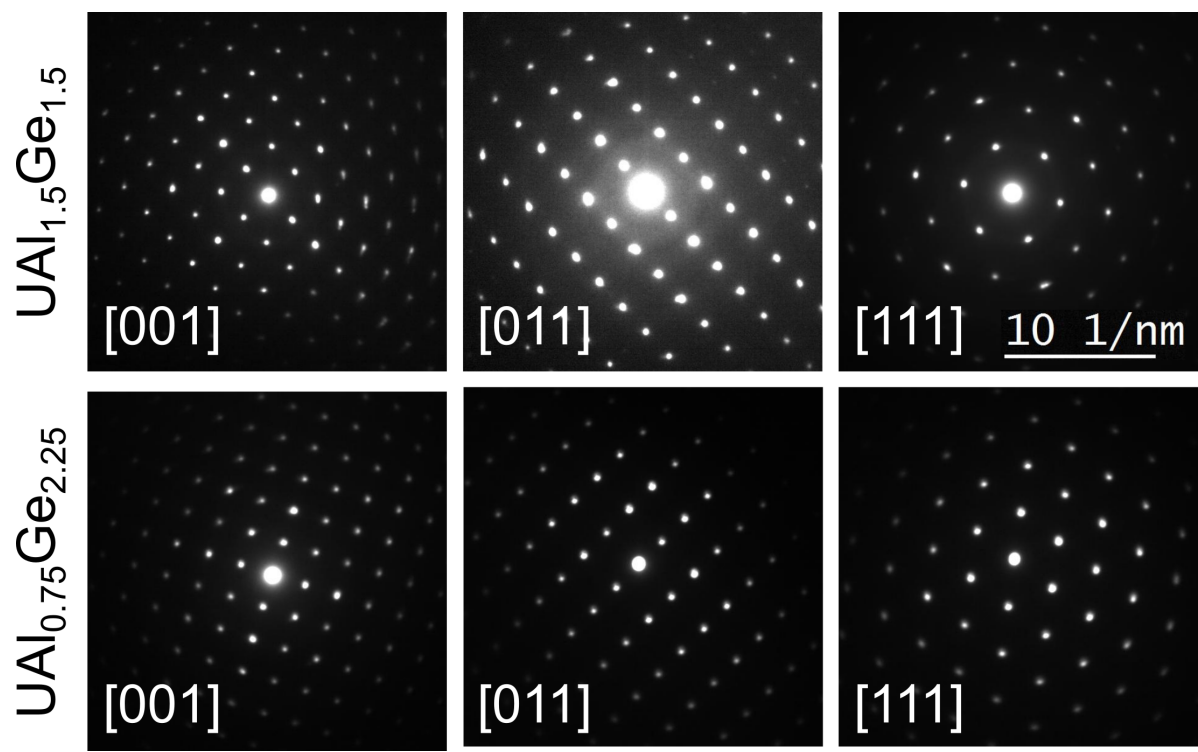

Figure 2: (Color online) Electron diffraction patterns of $\mathrm{UAl}_{1.5} \mathrm{Ge}_{1.5}$ (top) and $\mathrm{UAl}_{0.75} \mathrm{Ge}_{2.25}$ (bottom) along the [100] (right), [110] (middle) and [111] (left) zone axis confirming the absence of satellite reflections.

Thus, the non-linear lattice evolution is probably due to electronic effects changing the local structures on the mixed $\mathrm{Al} / \mathrm{Ge}$ site and preventing the chemical bonds to behave as expected from conventional solid-solution. Examples of such case can be found in $\mathrm{Ce}_{1-x} \mathrm{M}_{x} \mathrm{O}_{2}(\mathrm{M}=\mathrm{Sn}$ and $\mathrm{Ti}, 0 \geq \mathrm{x} \geq 0.5)$ where the difference in electronegativities between $\mathrm{Ce}$ and $\mathrm{Sn}$ provokes a splitting of $\mathrm{M}-\mathrm{O}$ distances in the first coordination sphere which affects the average distances accessible by diffraction experiments [22]. In order to study atom the local structures and valence states selectively for $U$ and Ge, EXAFS and HERFD $\mathrm{X}$-ray spectroscopy have been performed.

In Fig. 3 the experimental EXAFS signals are shown. Although at a first view the signals seem relatively simple, they are the results of a complex superimposition of several contributes as more visible for sample $\mathrm{UAl}_{2.25} \mathrm{Ge}_{0.75}$. The local structure of $\mathrm{U}$ from crystal data is formed by $12 \mathrm{Al} / \mathrm{Ge}$ forming a regular cuboctahedron and 6 more distant $\mathrm{U}$ forming a regular octahedra (Fig. 3, right 

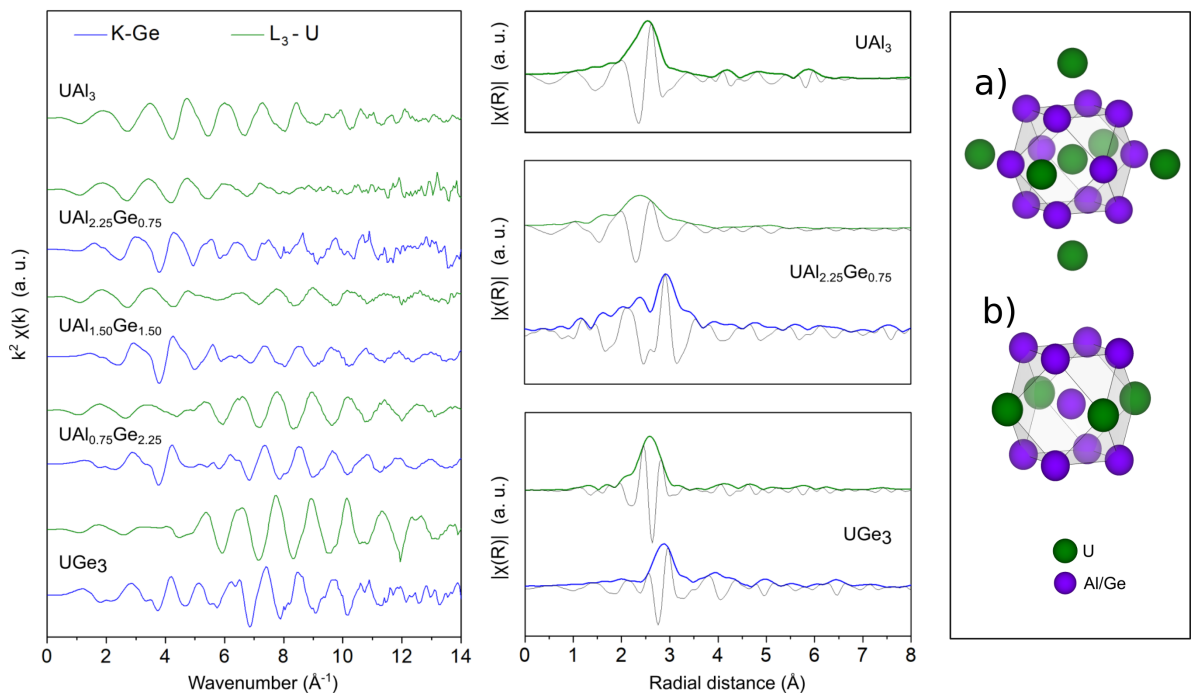

Figure 3: (Color Online) Left and central parts: experimental EXAFS data for $\mathrm{U}\left(\mathrm{Al}_{1-x} \mathrm{Ge}_{x}\right)_{3}$ solid solution at $\mathrm{U} \mathrm{L}_{3}$ (green curves) and Ge $\mathrm{K}$ (blue curves) edges. $\chi(\mathrm{k}) \mathrm{k}^{2}$ and imaginary part and magnitude Fourier transform of few selected compositions. Right side: Coordination spheres around $\mathrm{U}$ and Ge used as initial model for EXAFS refinements. (a) U-atom coordinated with $12 \mathrm{Al} / \mathrm{Ge}$ forming a regular cuboctahedron and 6 more distant $\mathrm{U}$ forming a regular octahedra (b) Ge-atom coordinated with $12 \mathrm{Al} / \mathrm{Ge}$ forming a regular cuboctahedron

side, part a). As a consequence the apparent single shell signal is generated by the interference pattern of three contributions, two from $\mathrm{Al}$ and $\mathrm{Ge}$ in the first coordination shell and the third from $\mathrm{U}$ in second coordination shell. In the case of Ge, local structure consists of a first coordination shell constituted by a regular cuboctahedron containing $4 \mathrm{U}$ and $8 \mathrm{Al} / \mathrm{Ge}$ atoms (Fig. 3, right side, part b), and a second shell formed by a regular octahedra of 6 Ge. However, in the EXAFS signal the second shell contribution is sufficiently separated from the first shell one, consequently, the fitting could be realized considering only the three contributions from the first shell.

In order to evaluate with the maximum precision the near-neighbor (NN) distances around $\mathrm{U}$ and Ge, EXAFS signal has been refined simultaneously for the two edges for every compositions taking in account the contribution of the atoms present in the two clusters in fig. 3. All the NN distances U-Al, U-Ge, 
Ge-Ge and Ge-Al were initially set equal with value derived from $d=a \sqrt{2} / 2$ where $a$ is the lattice parameter obtained from powder diffraction. For U-U contribution, the U-U distances were constrained to the value of $a$ and only the mean square relative displacements $\left(\sigma^{2}\right)$ were allowed to vary. For the other contributions, the degenerates $(N)$ of $\mathrm{Al}$ and Ge were constrained according to the stoichiometry, i.e. using a binomial distribution. The refined structural parameters were the NN distances along with their $\sigma^{2}$. Fig. 4 shows the quality of the fits within the $\mathrm{R}$ range corresponding to the first coordination spheres (1.0 - $3.75 \AA$ ) while Table 1 summarizes the values of the fitted parameters obtained after the refinements. It is worth of noticing, that although the relatively high number of parameters for the fit of a single signal, the correlation between parameters remain rather limited due to the fact that both edges are fitted simultaneously implying that structural parameters remain the same for both signals.

Table 1: Summary of the parameters obtained by combined least square refinements of $\chi(\mathrm{R})$ measured at the $\mathrm{U} \mathrm{L}_{3}$ and $\mathrm{Ge} \mathrm{K}$ egdes for the $\mathrm{U}\left(\mathrm{Al}_{1-x} \mathrm{Ge}_{x}\right)_{3}$ samples with $\mathrm{x}=0,0.25,0.5,0.75$ and 1. $S_{0}^{2}, \Delta E_{0}, N$ and $\sigma^{2}$ correspond to the passive electron reduction function, shift in the edge energy, degeneracy and mean square relative displacements, respectively. Constrained parameters are marked with *.

\begin{tabular}{|c|c|c|c|c|c|c|}
\hline & & $\mathrm{UAl}_{3}$ & $\mathrm{UAl}_{2.25} \mathrm{Ge}_{0.75}$ & $\mathrm{UAl}_{1.5} \mathrm{Ge}_{1.5}$ & $\mathrm{UAl}_{0.75} \mathrm{Ge}_{2.25}$ & $\mathrm{UGe}_{3}$ \\
\hline \multirow{3}{*}{$\mathrm{U}-\mathrm{L}_{3}$} & $S_{0}^{2}$ & $0.77(3)$ & $0.75(1)$ & $0.75(5)$ & $0.75(2)$ & $0.82(5)$ \\
\hline & $\Delta E_{0}(\mathrm{eV})$ & $5.6(3)$ & $5(1)$ & $6.2(7)$ & $4(1)$ & $5.2(7)$ \\
\hline & $N \mathrm{Al} / \mathrm{Ge}$ & $12 / 0^{*}$ & $9 / 3^{*}$ & $6 / 6^{*}$ & $3 / 9^{*}$ & $0 / 12^{*}$ \\
\hline \multirow{3}{*}{ Ge-K } & $S_{0}^{2}$ & l & $1.0(3)$ & $0.81(9)$ & $0.9(1)$ & $0.79(8)$ \\
\hline & $\Delta E_{0}(\mathrm{eV})$ & / & 2.99(1) & $3(1)$ & $1.9(6)$ & $2.3(7)$ \\
\hline & $N \mathrm{U} / \mathrm{Al} / \mathrm{Ge}$ & 1 & $4 / 6 / 2^{*}$ & $4 / 4 / 4^{*}$ & $4 / 2 / 6^{*}$ & $4 / 0 / 8^{*}$ \\
\hline \multirow{6}{*}{$\begin{array}{c}\text { bond } \\
\text { distances }\end{array}$} & $U-G e(\AA)$ & / & $2.945(6)$ & $2.946(3)$ & $2.951(1)$ & $2.970(1)$ \\
\hline & $\sigma^{2}\left(\AA^{2}\right)$ & / & $0.007(2)$ & $0.006(1)$ & $0.0067(2)$ & $0.0057(4)$ \\
\hline & $U-A l(\AA)$ & $3.022(1)$ & $3.017(5)$ & $3.011(3)$ & $2.984(7)$ & / \\
\hline & $\sigma^{2}\left(\AA^{2}\right)$ & $0.0069(6)$ & $0.008(1)$ & $0.007(1)$ & $0.011(4)$ & / \\
\hline & $U-U(\AA)$ & $4.2676^{*}$ & $4.2511^{*}$ & $4.2271^{*}$ & $4.2132^{*}$ & $4.2078^{*}$ \\
\hline & $\sigma^{2}\left(\AA^{2}\right)$ & $0.007(1)$ & $0.04(3)$ & $0.027(8)$ & $0.018(5)$ & $0.009(2)$ \\
\hline \multirow{2}{*}{$\begin{array}{l}\text { Agreement } \\
\text { factors }\end{array}$} & $\chi^{2}$ & 92.2 & 188.7 & 46.8 & 66.2 & 110.1 \\
\hline & R-factor & 0.021 & 0.039 & 0.023 & 0.007 & 0.016 \\
\hline
\end{tabular}


The $\chi(\mathrm{R})$ of $\mathrm{UAl}_{3}$ and $\mathrm{UGe}_{3}$, shown in Figure 4 (a) and (e), could be fitted expected from the previous solid solution works on local structure.
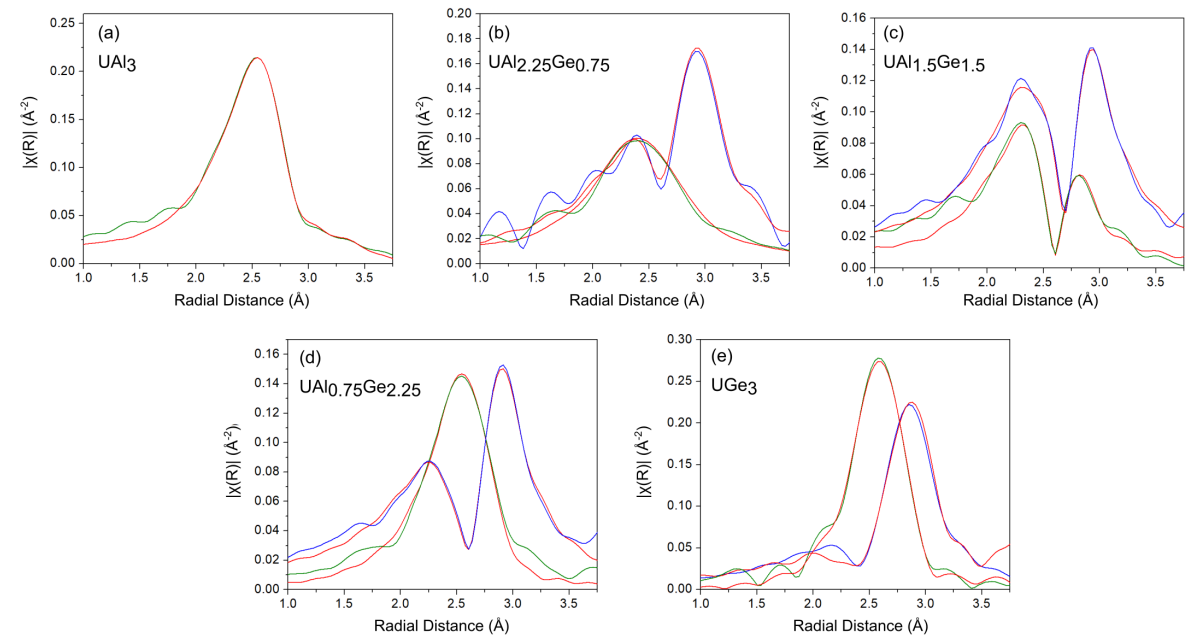

Figure 4: (Color Online) Fits of the $\chi(\mathrm{R})$ for all the compositions studied in the 1.0 to $3.75 \AA$ range corresponding to the first coordination sphere of $\mathrm{U}$ - and Ge-atoms in the $\mathrm{U}\left(\mathrm{Al}_{1-x} \mathrm{Ge}_{x}\right)_{3}$ solid solution. $\chi(\mathrm{R})$ of the $\mathrm{Ge} \mathrm{K}$ and $\mathrm{U} \mathrm{L}_{3}$ edges are plotted in blue and green, respectively. Results of the fits are plotted in red.

Fig. 5 shows the evolution of the U-Ge and U-Al distances as a function of the concentration $x$ of $\mathrm{Ge}$ in $\mathrm{U}\left(\mathrm{Al}_{1-x} \mathrm{Ge}_{x}\right)_{3}$ along with the average $\mathrm{U}-(\mathrm{Al} / \mathrm{Ge})$ distance determined by XRD and by a weighted average of the distances obtained by EXAFS analysis, calculated with:

$$
\mathrm{U}-\mathrm{Al} / \mathrm{Ge}=\mathrm{U}-\mathrm{Ge} \cdot x+\mathrm{U}-\mathrm{Al} \cdot(1-x)
$$


With increasing the Ge-content in $\mathrm{UAl}_{3}$, the $\mathrm{U}-\mathrm{Al}$ distance was found to shorten from 3.022(4) $\AA$ in $\mathrm{UAl}_{3}$ to 2.98(2) $\AA$ in $\mathrm{UAl}_{0.75} \mathrm{Ge}_{2.25}$. As mentioned before, this is the typical behavior of conventional solid solutions where only a light shortening of distance, due the increasing crystal strain, is expected. On the other hand, the U-Ge distance, in discrepancy with crystallography prediction where the distance is supposed to increase due to the bigger cell parameter of $\mathrm{UAl}_{3}$, decreases with increasing $\mathrm{Al}$ concentration from $2.969 \AA$ in $\mathrm{UGe}_{3}$ to $2.941 \AA$ in $\mathrm{UAl}_{2.25} \mathrm{Ge}_{0.75}$ ( $\approx-1 \%$ shortening$)$.

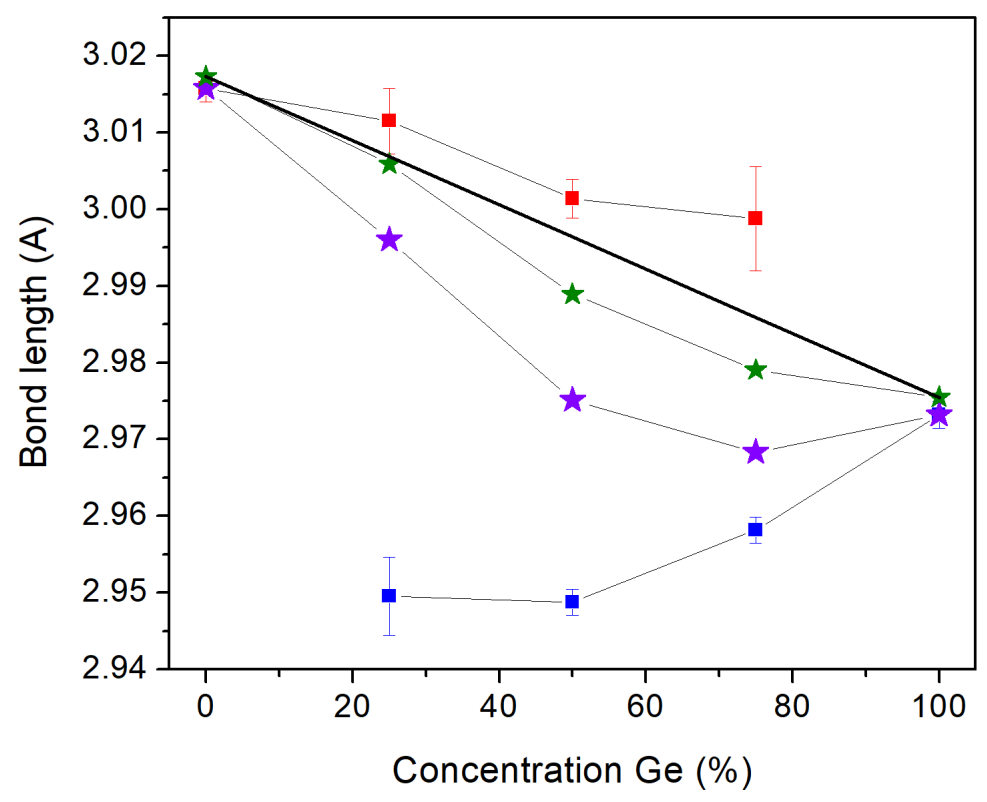

Figure 5: (Color Online) Evolution of the U-Al (blue squares), U-Ge (red squares) and average $\mathrm{U}-\mathrm{Al} / \mathrm{Ge}$ distances (purple stars) obtained from EXAFS as a function of the Ge concentration $x$ in $\mathrm{U}\left(\mathrm{Al}_{1-x} \mathrm{Ge}_{x}\right)_{3}$ intermetallics. Distances determined from XRD (green stars) and the linear relation expected from the Vegard's law (black line) are shown for comparison of the evolution obtained by the two methods.

As a consequence the average $\mathrm{U}-\mathrm{Al} / \mathrm{Ge}$ distance, strongly deviates from the linear evolution expected from the Vegard law. Remarkably, the trend of the 
deviation calculated from EXAFS data is in good agreement with the deviation measured by XRD since both are negative and with the maximum deviation for the $\mathrm{UAl}_{1.5} \mathrm{Ge}_{1.5}$ and $\mathrm{UAl}_{0.75} \mathrm{Ge}_{2.25}$ compositions. However, the extent of such

investigated the same solid solution by high resolution analysis of fluorescence emission, determining the number of $5 f$ electrons of uranium to 2.54 for $\mathrm{UGe}_{3}$ 
and 2.26 for $\mathrm{UAl}_{3}$ (i.e. depopulation of $0.28 \mathrm{e}^{-}$).
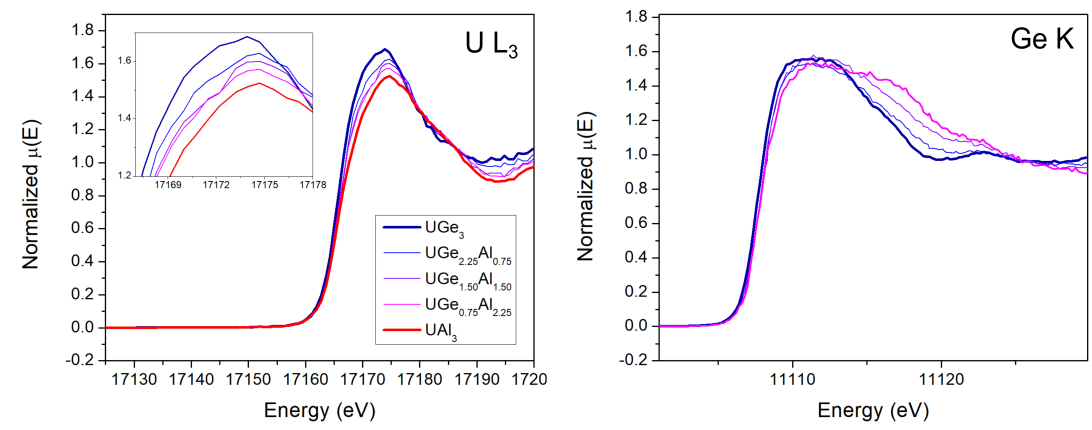

Figure 6: (Color Online) HERFD of the $\mathrm{U} \mathrm{L}_{3}$ XANES for $\mathrm{U}\left(\mathrm{Al}_{1-x} \mathrm{Ge}_{x}\right)_{3}$ with $\mathrm{x}=0,0.25,0.5$, 0.75 and 1 . The inset is a close up view showing the continuous evolution in energy of the peak edge toward higher energies with increasing $\mathrm{Al}$ content.

The Ge K edge is dominated by the $1 s \rightarrow 4 p$ transition. In such case the spectral change is more limited than $\mathrm{U}$, the edge is almost unaffected and the increase of $\mathrm{Al}$ concentration generates a minor decrease of the white line peak and a clear increase of the shoulder at $11118 \mathrm{eV}$. XANES simulations using the structure of $\mathrm{UGe}_{3}$ and an $\mathrm{UGe}_{2} \mathrm{Al}$ model using experimental interpolated cell parameters and a $P 4 / \mathrm{mmm}$ superstructure are able to reproduce the main features of the spectra evolution (see SI fig. 1, 2 and 3). Using such approximation is possible to compare the spectra characteristics with the density of states obtained during the same calculation. It emerges that at Ge K edge, the two peaks at 11110 and $11118 \mathrm{eV}$ that are mainly due to Ge levels with $p$ character, fall in the same energy range than two peaks of $\mathrm{U}$ dos with $d$ character suggesting that $\mathrm{Al}$ in the solid solution actively affect the hybridization of $\mathrm{U} d$ levels with the Ge $p$ levels.

The depopulation of the U- $5 f$ orbitals with increasing aluminum content is supported by specific heat measurements (fig. 7). Despite some noise at the lowest temperatures in the signal of $\mathrm{UAl}_{3}$ due to the non-congruent melting of this phase $[14,7]$ inducing the appeareance of porosity and cracks after annealing, the specific heat follows up to about $10 \mathrm{~K}$ the expected law for a regular 
metal:

$$
\frac{C_{p}}{T}=\gamma+\beta T^{2}
$$

where $\gamma$ is the Sommerfeld coefficient and $\beta$ the Debye component of the specific heat.

The specific heat of $\mathrm{UAl}_{3}$ agrees with previous reports, showing an almost flat variation of $\mathrm{C}_{p} / \mathrm{T}=\mathrm{f}\left(\mathrm{T}^{2}\right)$ below $100 \mathrm{~K}^{2}\left(\beta=0.118 \mathrm{~mJ} \mathrm{~mol}^{-1} \mathrm{~K}^{-4}\right)$ and a Sommerfeld coefficient of $43 \mathrm{~mJ} \mathrm{~mol}^{-1} \mathrm{~K}^{-2}\left(41,41.6,43.2\right.$ and $47 \mathrm{~mJ} \mathrm{~mol}^{-1} \mathrm{~K}^{-2}$ for Scheidt [11], van Maaren [28], Cornelius [29] and Aoki [30] et al., respectively). The values obtained for $\mathrm{UGe}_{3}\left(\beta=0.49 \mathrm{~mJ} \mathrm{~mol}^{-1} \mathrm{~K}^{-4}, \gamma=20.2 \mathrm{~mJ} \mathrm{~mol}^{-1} \mathrm{~K}^{-2}\right)$ are also in line with literature data $\left(\beta=0.455 \mathrm{~mJ} \mathrm{~mol}^{-1} \mathrm{~K}^{-4}[28]-\gamma=20.4\right.$ $\left.{ }_{260}[28,31], 20.5 \mathrm{~mJ} \mathrm{~mol}^{-1} \mathrm{~K}^{-2}[11]\right)$. With the exception of $\mathrm{UAl}_{2.25} \mathrm{Ge}_{0.75}, \beta$ increases regularly with the Ge-content, in agreement with the heavier molar mass of this element. $\gamma$ follows an opposite increase with the Al-content along the solid solution. Such an increase highlight an enhanced contribution of the electrons to the specific heat which is usually attributed to a higher delocalization of the U-5f electrons, in agreement with the spectroscopic observations.

The anomalous behavior of $\mathrm{UAl}_{2.25} \mathrm{Ge}_{0.75}$, confirmed by $\mathrm{C}_{p}$ measurements on several pieces with this composition, remains unexplained yet.

\section{Conclusion}

In the present work the origin of the deviation from the Vegard's law for $\mathrm{U}\left(\mathrm{Al}_{1-x} \mathrm{Ge}_{x}\right)_{3}$ has been investigated experimentally by long and local range order techniques. The deviation has been proven to be based on actual bond length variation while the possible long range ordering phenomena as $\mathrm{UAl}_{3}$ $\mathrm{USi}_{3}$ has been excluded by the absence of superstructures or diffuse scattering in electron diffraction. Indeed the deviation is mainly related to a decrease 275 of U-Ge bond length induced by the increase of Al concentration in the solid solution.

HERFD XANES and specific heat measurements show that such unexpected decrease of bond length is related to the depopulation of the $\mathrm{U} 5 f$ levels (around 

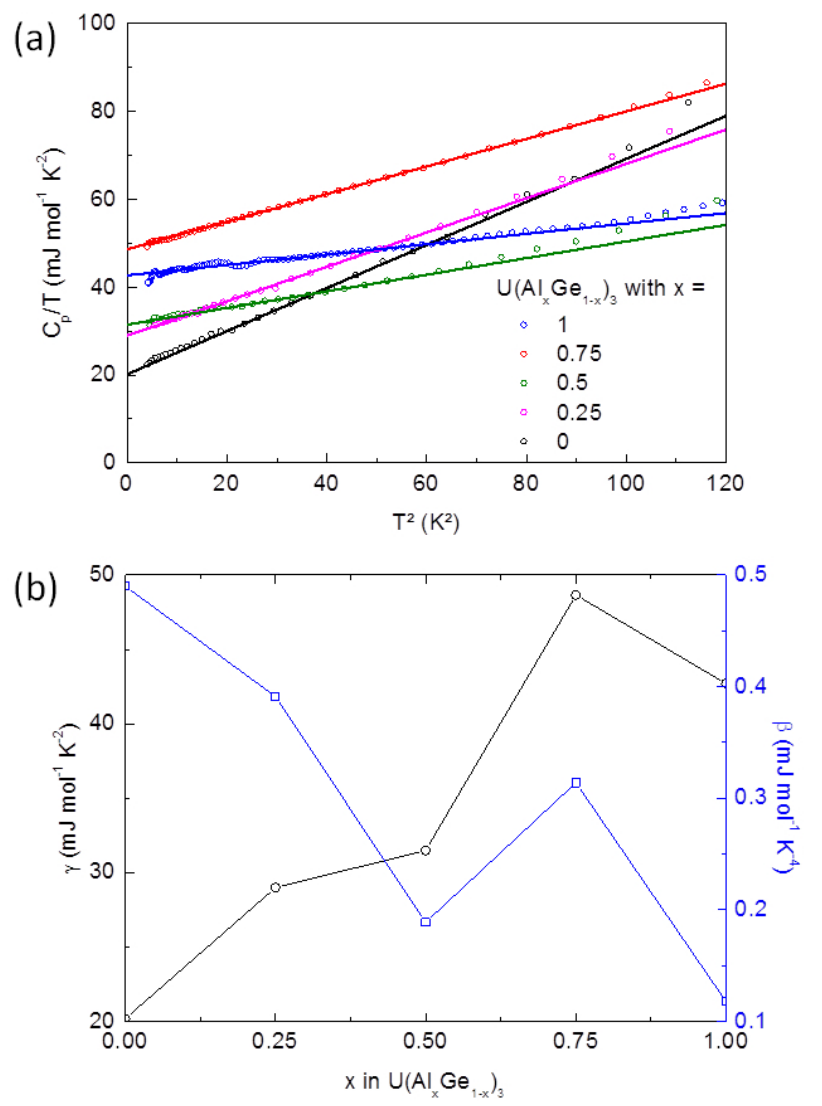

Figure 7: (Color Online) (a) Thermal dependence of the specific heat of $\mathrm{UAl}_{x} \mathrm{Ge}_{3-x}$ for $\mathrm{x}$ $=0,0.25,0.5,0.75$ and 1 (symbols) and linear fit according to eq. (3); (b) Variation of the $\gamma$ (left) and $\beta$ (right) parameters with the chemical composition, extracted from these fits (the solid lines are guides for the eyes). The standard deviations on the values are below the thickness of the symbols.

$0.2 \mathrm{e}^{-}$) suggesting that the deviation from Vegard's law is caused by valence instability in agreement with the work by Tyunis et al. [6].

Finally, such valence instability, in accordance with XANES simulations, seem to be related to the hybridization of Ge $4 p$ levels with $\mathrm{U} 6 d$ levels. 


\section{Acknowledgements}

Vincent Dorcet is acknowledged for TEM experiments performed on THEMIS

platform part of the ScanMAT unit (UMS 2001, University of Rennes 1), which received a financial support from the European Union (CPER-FEDER 2007-2014).

\section{References}

[1] W. C. Thurber, R. Beaver, Development of silicon-modified 48 wt.\% ual alloys for aluminum plate-type fuel elements, Tech. rep., Oak Ridge National Lab., Tenn. (1959). doi:10.2172/4260852.

[2] E. Perez, D. Keiser, Y. Sohn, Phase development in a u-7wt. \% mo vs. al-7wt. \% ge diffusion couple, Journal of Nuclear Materials 441 (1) (2013) 159 - 167. doi:https://doi.org/10.1016/j.jnucmat.2013.05.069.

[3] D. Rabin, R. Z. Shneck, G. Rafailov, I. Dahan, L. Meshi, E. Brosh, Thermodynamic modeling of al $-\mathrm{u}-\mathrm{x}(\mathrm{x}=\mathrm{si}, \mathrm{zr})$, Journal of Nuclear Materials 464 (2015) 170-184.

[4] G. Rafailov, I. Dahana, L. Meshi, Acta Cryst. B70 (2014) 580.

[5] H. J. Ryu, Y. S. Kim, G. L. Hofman, J. M. Park, C. K. Kim, Heats of formation of (u, mo) al3 and $\mathrm{u}$ (al, si) 3, Journal of nuclear materials 358 (1) (2006) 52-56.

[6] A. V. Tyunis, V. A. Shaburov, Y. P. Smirnov, A. E. Sovestnov, Valence instability of uranium in U(Al1-x Gex)3, Physics of the Solid State 39 (9) (1997) 1337-1340. doi:10.1134/1.1130075.

[7] C. Moussa, Z. ElSayah, G. Chajewski, A. Berche, V. Dorcet, A. Pikul, M. Pasturel, L. Joanny, B. Stepnik, O. Tougait, J. Solid State Chem. 243 (2016) 168.

[8] E. T. Teatum, Compilation of calculated data useful in predicting metallurgical behavior of the elements in binary alloy systems, Los Alamos 
Scientific Laboratory of the University of California, 1968, citation Key: teatumCompilationCalculatedData1968.

[9] S. S. Batsanov, Metallic radii of nonmetals, Russian Chemical Bulletin 43 (2) (1994) 199-201. doi:10.1007/BF00695809.

[10] B. Cordero, V. Gómez, A. E. Platero-Prats, M. Revés, J. Echeverría, E. Cremades, F. Barragán, S. Alvarez, Covalent radii revisited, Dalton Trans. (2008) 2832-2838doi:10.1039/B801115J.

[11] E.-W. Scheidt, G. Fraunberger, J. Rieger, A. Mielke, W. Kim, G. Stewart, J Alloys Compd. 218 (1995) 5.

[12] E. Burzo, P. Lucaci, Solid State Commun. 56 (1985) 537.

[13] L. Vegard, Z. Phys. 5 (1921) 17.

320 [14] L. Pauling, M. L. Huggins, Covalent Radii of Atoms and Interatomic Distances in Crystals containing Electron-Pair Bonds, Zeitschrift für Kristallographie - Crystalline Materials 87 (1-6) (1934) 205. doi:10.1524/zkri. 1934.87 .1 .205

[15] J. C. Mikkelsen, J. B. Boyce, Phys. Rev. Lett. 49 (1982) 1412.

325 [16] J. Rodriguez-Carvajal, Physica B 192 (1993) 55.

[17] B. Sitaud, P. L. Solari, S. Schlutig, I. Llorens, H. Hermange, J. Nucl. Mater. $425(2012) 238$.

[18] B. Ravel, M. Newville, J. Synchrotron Rad. 12 (2005) 537.

[19] H. N. O. Tougait, Intermetallics 12 (2004) 219.

[20] J. F. Jr., G. H. Lander, J. Brown, A. Delapalme, Acta Cryst. 37 (1981) 558.

[21] M. Castellanos, A. R. West, J. Chem. Soc. Faraday Trans. 76 (0) (1980) 2159-2169. doi:10.1039/F19807602159. 
[22] T. Baidya, P. Bera, O. Krocher, O. Safonova, P. M. Abdala, B. Gerke,

[23] J. A. v. Bokhoven, C. Lamberti (Eds.), X-ray absorption and X-ray emission spectroscopy: theory and applications, John Wiley \& Sons, Inc, Chichester, West Sussex, 2015.

[27] K. O. Kvashnina, H. C. Walker, N. Magnani, G. H. Lander, R. Caciuffo, Resonant x-ray spectroscopy of uranium intermetallics at the $\$\{\mathrm{M}\}-\{4,5\} \$$ edges of uranium, Phys. Rev. B 95 (24) (2017) 245103. doi:10.1103/ PhysRevB.95.245103.

360

[24] C. H. Booth, Y. Jiang, D. L. Wang, J. N. Mitchell, P. H. Tobash, E. D. Bauer, M. A. Wall, P. G. Allen, D. Sokaras, D. Nordlund, T.-C. Weng, M. A. Torrez, J. L. Sarrao, Multiconfigurational nature of $5 \mathrm{f}$ orbitals in uranium and plutonium intermetallics, Proceedings of the National Academy of Sciences 109 (26) (2012) 10205-10209. doi:10.1073/pnas.1200725109.

[25] C. H. Booth, S. A. Medling, Y. Jiang, E. D. Bauer, P. H. Tobash, J. N. Mitchell, D. K. Veirs, M. A. Wall, P. G. Allen, J. J. Kas, D. Sokaras, D. Nordlund, T. C. Weng, Delocalization and occupancy effects of $5 \mathrm{f}$ orbitals in plutonium intermetallics using L3-edge resonant X-ray emission spectroscopy, Journal of Electron Spectroscopy and Related Phenomena 194 (2014) 57-65. doi:10.1016/j.elspec. 2014.03.004.

[26] C. H. Booth, S. A. Medling, J. G. Tobin, R. E. Baumbach, E. D. Bauer, D. Sokaras, D. Nordlund, T.-C. Weng, Probing $\$ 5 f \$$-state configurations in $\$\{\backslash \operatorname{mathrm}\{\mathrm{URu}\}\}_{-}\{2\}\{\backslash \operatorname{mathrm}\{\mathrm{Si}\}\}_{-}\{2\} \$$ with $\mathrm{U} \$\{\mathrm{~L}\}_{-}\{\backslash \operatorname{text}\{\mathrm{III}\}\} \$-$ edge resonant x-ray emission spectroscopy, Phys. Rev. B 94 (4) (2016) 045121. doi:10.1103/PhysRevB.94.045121.

M. Van Maaren, H. Van Daal, K. Buschow, C. Schinkel, High electronic specific heat of some cubic ux3 intermetallic compounds, Solid State Communications 14 (2) (1974) 145-147. 
[29] A. Cornelius, A. Arko, J. Sarrao, J. Thompson, M. Hundley, C. Booth, N. Harrison, P. Oppeneer, Electronic properties of u x 3 ( $\mathrm{x}=\mathrm{ga}$, al, and sn) compounds in high magnetic fields: Transport, specific heat, magnetization, and quantum oscillations, Physical Review B 59 (22) (1999) 14473.

[30] D. Aoki, N. Watanabe, Y. Inada, R. Settai, K. Sugiyama, H. Harima, T. Inoue, K. Kindo, E. Yamamoto, Fermi surface properties of the enhanced pauli paramagnet ual 3, Journal of the Physical Society of Japan 69 (8) (2000) 2609-2614.

[31] A. Pikul, R. Troć, A. Czopnik, H. Noël, Low-temperature specific heat of uranium germanides, Journal of Magnetism and Magnetic Materials 360 (2014) 217-221. 


\section{Supplementary}

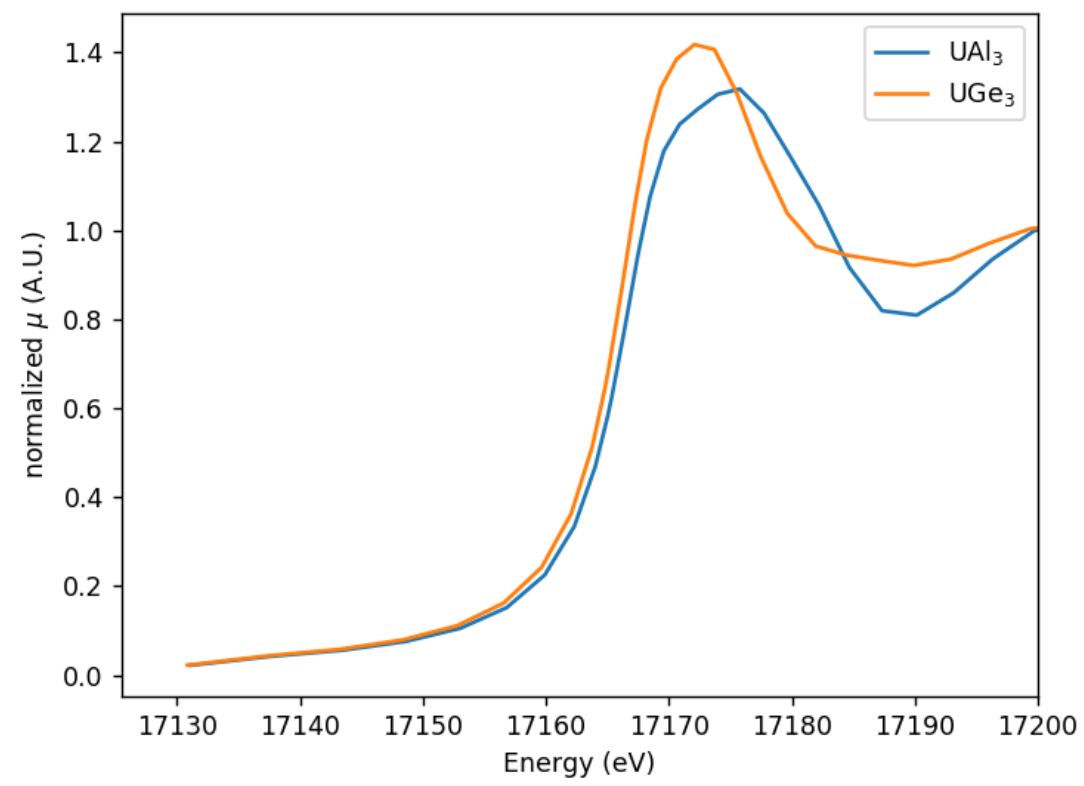

Figure 8: (Color Online) U edge. Simulation of of $\mathrm{UGe}_{3}$ and $\mathrm{UAl}_{3}$ curve blue and orange respectively. As for experimental the $\mathrm{UAl}_{3}$ whiteline is broader and blueshift 


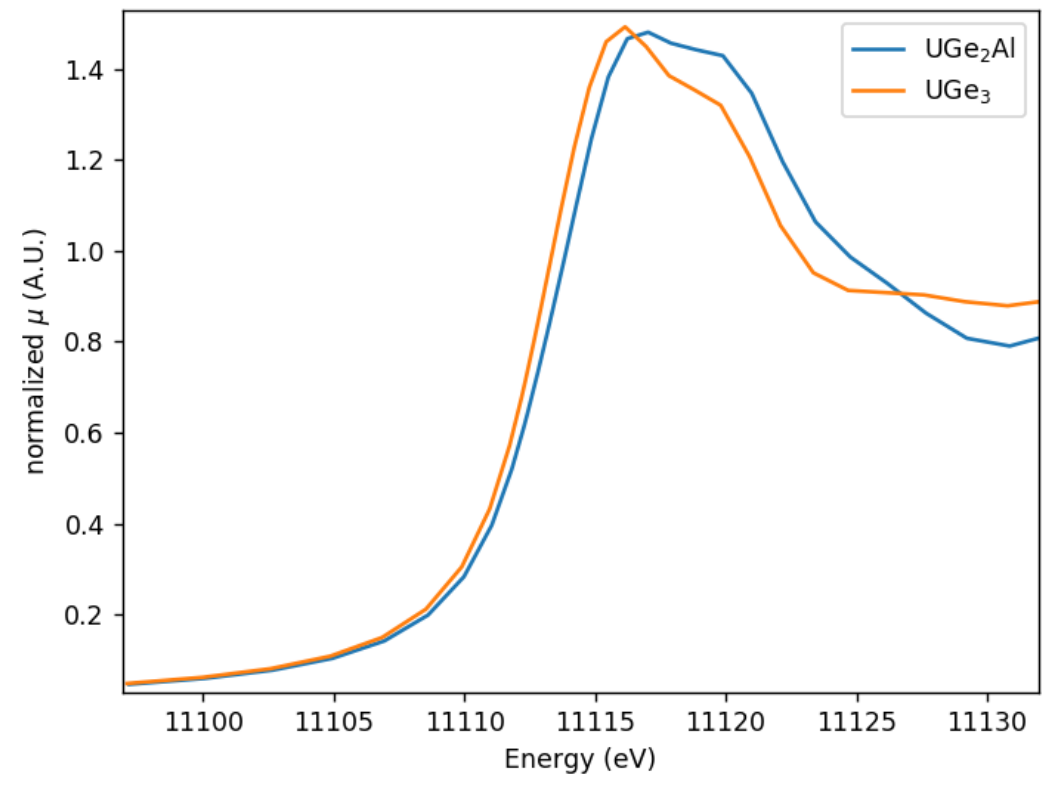

Figure 9: (Color Online) Ge K-edge simulation $\mathrm{UGe}_{2} \mathrm{Al}$ and $\mathrm{UGe}_{3}$ curve blue and orange respectively. Study of the modification of Ge edge as a function of $\mathrm{Al}$ concentration. The $\mathrm{UGe}_{2} \mathrm{Al}$ cluster has been generating using $P 4 / \mathrm{mmm}$ superstructure 


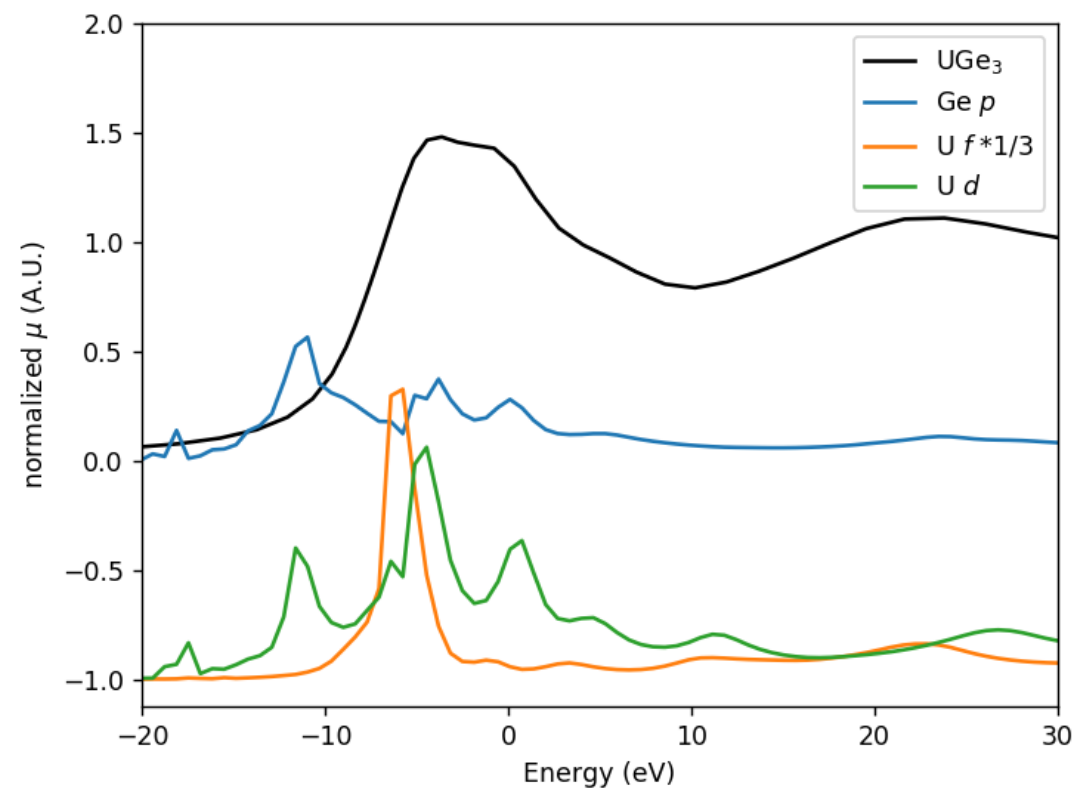

Figure 10: (Color Online) Ge K-edge simulation of $\mathrm{UGe}_{2} \mathrm{Al}$ and related symmetry filtered projected density of state for each atoms. 


\section{Unusual variation of the U-Ge distance explains $\mathrm{U}\left(\mathrm{Al}_{1-\mathrm{x}} \mathrm{Ge}_{\mathrm{x}}\right)_{3}$ deviation from Vegard's law}

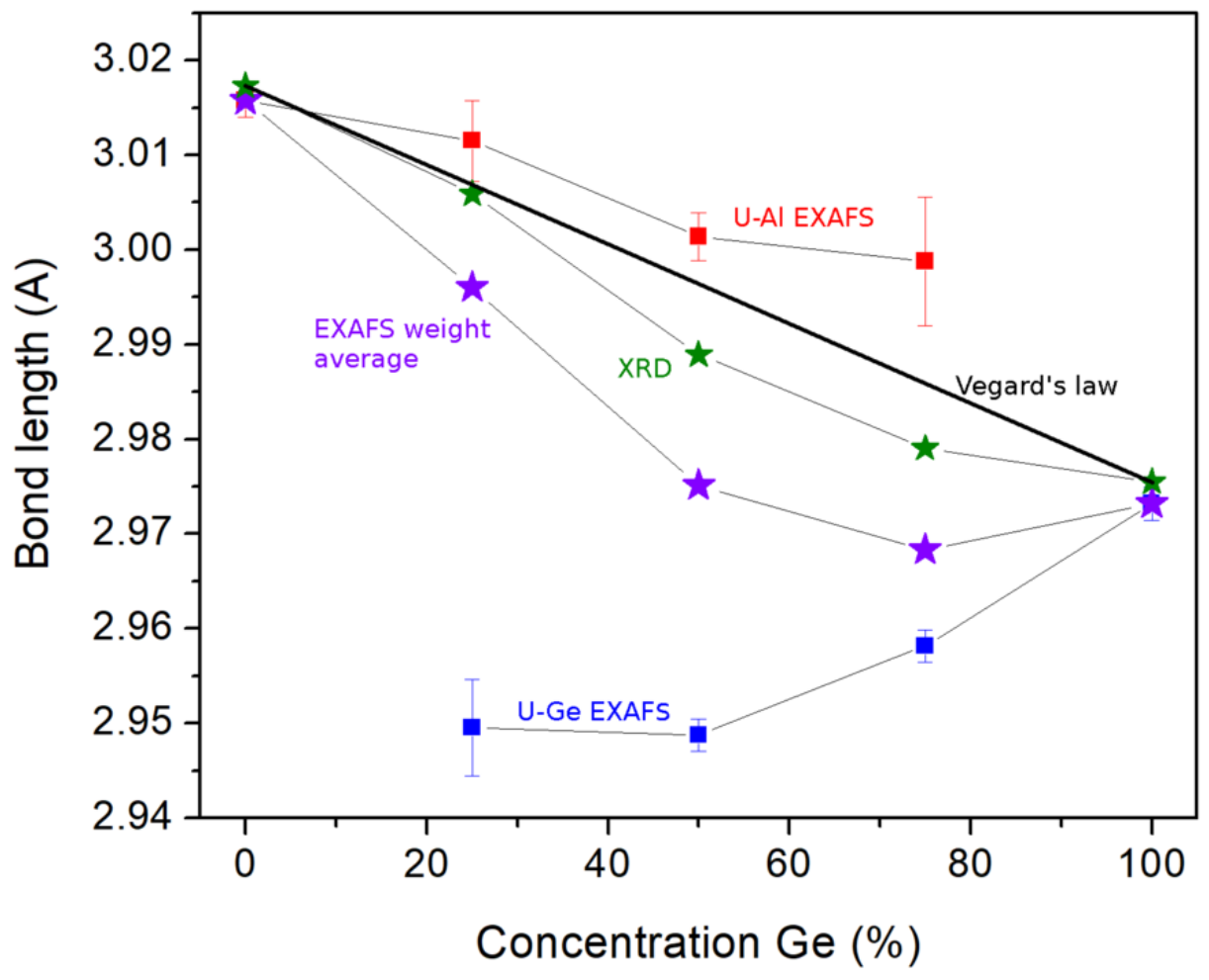

